\title{
MicroRNA-216a suppresses the proliferation and migration of human breast cancer cells via the Wnt/及-catenin signaling pathway
}

\author{
QING XIE* ${ }^{*}$, SHUAI WANG ${ }^{*}$, YUE ZHAO, ZHENCHAO ZHANG, CHUAN QIN and XIANJUN YANG \\ School of Basic Medical Sciences, Xinxiang Medical University, Xinxiang, Henan 453003, P.R. China
}

Received April 21, 2017; Accepted September 5, 2018

DOI: $10.3892 /$ or.2019.7050

\begin{abstract}
The aim of the present study was to investigate the potential anticancer effects of microRNA-216a on the growth of human breast cancer and the possible underlying mechanisms. The results demonstrated that serum microRNA-216a was significantly decreased in patients with breast cancer compared with healthy controls. MicroRNA-216a overexpression led to a decrease in cell proliferation and migration, as well as increases in apoptosis, caspase-3/8 activities, Bax expression and p53 protein expression in MCF-7 cells. It was also revealed that microRNA-216a suppressed Wnt and $\beta$-catenin expression in MCF-7 cells. The anticancer effects of microRNA-216a were reversed by anti-microRNA-216a by promoting the $\mathrm{Wnt} / \beta$-catenin signaling pathway. Inactivation of the Wnt pathway increased the anticancer effects of microRNA-216a in MCF-7 cells. Collectively, the results of the present study indicated that microRNA-216a suppressed the growth of human breast cancer cells by targeting the Wnt/ $\beta$-catenin signaling pathway.
\end{abstract}

\section{Introduction}

Breast cancer is one of the most common malignancies affecting women worldwide, accounting for $25 \%$ of newly diagnosed cancer cases and $15 \%$ of cancer-associated mortalities in women. As such, breast cancer represents a major threat to life expectancy and quality of life, as well as being a socioeconomic burden (1). Data from the Global Cancer Report (2014) revealed that 1.677 million new cases of breast cancer were diagnosed in 2014; of these, 187,000 cases were

Correspondence to: Dr Qing Xie, School of Basic Medical Sciences, Xinxiang Medical University, 601 Jinsui Road, Xinxiang, Henan 453003, P.R. China

E-mail: xfcjr695408@126.com

${ }^{*}$ Contributed equally

Key words: microRNA-216a, human breast cancer cells, Wnt, $\beta$-catenin reported in China, accounting for $11.2 \%$ of novel breast cancer cases worldwide. According to the China Cancer Registration Annual Report in 2014, the morbidity of breast cancer in Chinese women in 2012 reached 42.55/100,000 (2). At present, China has a relatively low incidence of breast cancer; however, China has a large population base and the morbidity of breast cancer in China has been increasing since the 1990s. Breast cancer now has the highest morbidity of cancers in Chinese women and is the 6th leading cause of cancer-associated mortality $(3,4)$.

The Wnt protein family is a group of highly conserved secreted signaling molecules that regulate intercellular signal transduction during embryogenesis. In recent years, the various Wnt protein-triggered signaling pathways have been investigated (5). Mutations of the Wnt gene and Wnt signaling pathway molecules can induce developmental defects, while aberrant Wnt signal transduction can lead to the development of human diseases, including tumors (6). It has been demonstrated that imbalances in the Wnt signaling pathway are associated with the genesis and development of breast cancer (7).

As the key transfer factor of the Wnt signaling pathway, $\beta$-catenin is expressed in a number of human tumors and its carcinogenic potential has been extensively studied in vitro as well as in animal experiments in vivo (8). Nuclear aggregation of $\beta$-catenin is frequently considered to be a marker of Wnt/ $\beta$-catenin signaling pathway activation, while its stability and accumulation within the cells is regarded as one of the most critical events in the pathway (9). In the presence of Wnt signaling, GSK-3 $\beta$ activity is inhibited and a large amount of $\beta$-catenin accumulates within the cells, entering the nucleus and initiating target gene expression (7).

As the downstream IE-targeted gene of the Wnt/ $\beta$-catenin signaling pathway, cyclin D1 is believed to promote G1 to $\mathrm{S}$ stage transition, initiate DNA synthesis, and participate in cell proliferation, differentiation and apoptosis in normal cells. Excessive cyclin D1 expression leads to abnormal cell cycle control and is associated with the genesis and development of a number of human tumors (10). It has been demonstrated that the cyclin D1 gene is an important downstream target gene of the Wnt/ $\beta$-catenin signaling pathway and that cyclin D1 overexpression in numerous human tumors is associated with the aberrant expression of $\beta$-catenin and mutations in the Wnt/ $\beta$-catenin signaling pathway $(11,12)$. Aberrant expression 
of $\beta$-catenin has been revealed to be associated with cyclin D1 and c-myc overexpression in breast cancer (11).

MicroRNAs (miRNAs) are involved in almost all cell biological processes (13). It has recently been reported that a number of miRNAs are aberrantly expressed in tumor tissues, including breast cancer (14). In addition, they serve different roles in the various stages of tumor metastasis, including tumor cell adhesion, migration, invasion and angiogenesis (14). The carcinogenic and antitumor effects of miRNA in breast cancer have been established (15). However, their roles in breast cancer metastasis have only been proposed in the past few years. Zhang et al suggested that microRNA216a suppresses the proliferation, migration and invasion of glioma cells via the $\mathrm{Wnt} / \beta$-catenin signaling pathway (16). MicroRNA-216a may act as a regulatory factor in human breast cancer cells. Therefore, the aim of the present study was to assess the potential effects of microRNA-216a on the growth of human breast cancer cells and the possible underlying mechanism.

\section{Materials and methods}

Human samples. Patients with breast cancer (females, 55-67 years old) and normal volunteers were recruited from the School of Basic Medical Sciences of Xinxiang Medical University (Xinxiang, China) between December 2016 and January 2017. The characteristics of the patients are displayed in Table I. All clinical samples ( 6 breast cancer serum and 6 normal volunteer serum) were centrifuged at $1,000 \mathrm{x} \mathrm{g}$ for $10 \mathrm{~min}$ at $4^{\circ} \mathrm{C}$. The serum specimens were snap-frozen immediately after collection and were stored at $-80^{\circ} \mathrm{C}$ until use. All experimental protocols were approved by the Institutional Review Board of the Department of Laboratory Animal Science of School of Basic Medical Sciences, Xinxiang Medical university (Xinxiang, China). Written informed consent was obtained from all participants.

RNA extraction and quantitative real-time PCR. Total RNA was extracted using TRIzol reagent (Invitrogen; Thermo Fisher Scientific, Inc., Waltham, MA, USA) and used as a template to generate cDNA using a PrimeScript ${ }^{\mathrm{TM}}$ RT Reagent kit (DRR047A; Takara, Tokyo, Japan). The RT primer was as follows: 5'-GTCGTATCCAGTGCG-3'. PCR was performed using a miRCURY LNA ${ }^{\mathrm{TM}}$ Universal RT miRNA PCR kit (Exiqon, Vedbaek, Denmark) and SYBR Green master mix (Exiqon) on an ABI 7500 system (Applied Biosystems; Thermo Fisher Scientific, Inc.). The microRNA-216a primers were as follows: forward, 5'-ATCCAGTGCGTGTCGTG-3' and reverse, 5'-TGCTTAATCTCAGCTGGCA-3'.

Cell lines and cell transfection. The human breast cancer MCF-7 cells were obtained from the American Type Culture Collection (ATCC) and maintained in RPMI-1640 medium (Gibco; Thermo Fisher Scientific, Inc.) supplemented with $10 \%$ fetal bovine serum (FBS, Gibco; Thermo Fisher Scientific, Inc.) and 1\% antibiotics (100 IU/ml penicillin and $100 \mu \mathrm{g} / \mathrm{ml}$ streptomycin) and maintained in a $37^{\circ} \mathrm{C}$ incubator with a humidified atmosphere of $5 \% \mathrm{CO}_{2}$. MicroRNA-216a, anti-microRNA-216a and negative control plasmids were purchased from Sangon Biotech Co., Ltd.
Table I. Basic characteristics of the patients with breast cancer.

\begin{tabular}{lcc}
\hline Variables & Patients (6) & Normal (6) \\
\hline Age (yrs.) & & \\
$\quad 55$ & 3 & 4 \\
$>55$ & 3 & 0 \\
Edmondson grade & & \\
I & 0 & \\
II & 2 & \\
III & 4 & \\
\hline
\end{tabular}

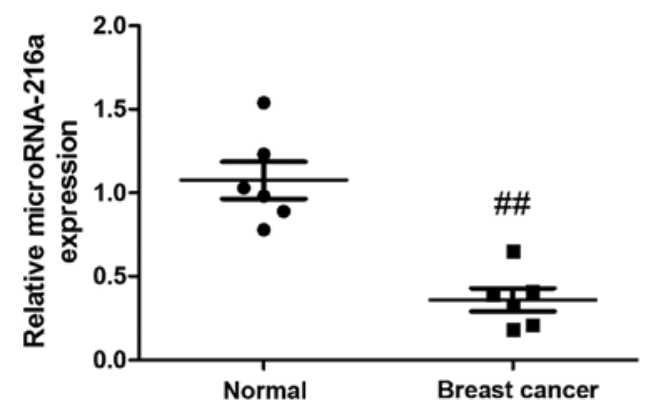

Figure 1. MicroRNA-216a expression in breast cancer serum and normal volunteer serum. Control, normal volunteer serum $(n=6)$; Breast cancer, breast cancer serum $(\mathrm{n}=6) .{ }^{\#} \mathrm{P}<0.01$ compared with normal volunteer serum group.

(Shanghai, China). The sequences were as follows: miR-216a, 5'-TCACAGTTCCCAGCTGAGATTA-3'; anti-miR-216a, 5'-GCAGCGCCTGTGAGAGGGATGAAAA-3'; and negative control, 5'-CCCCCCCCCCCCCC-3'. Cell transfection was performed with $100 \mathrm{nM}$ of microRNA-216a, anti-microRNA-216a and negative control plasmids using Lipofectamine $^{\mathrm{TM}} 2000$ (Invitrogen) according to the manufacturer's instructions. Next, after transfection for $6 \mathrm{~h}, 20 \mu \mathrm{M}$ of PNU-74654 was added to the cells for $48 \mathrm{~h}$.

Determination of cytotoxicity. After transfection for 24, 48 and $72 \mathrm{~h}, \mathrm{MCF}-7$ cells were seeded in a 96-well-plate ( $1 \times 10^{4}$ cells). MTT solution $(20 \mu \mathrm{l})$ was added to every well and incubation followed for $4 \mathrm{~h}$ at $37^{\circ} \mathrm{C}$. Then $150 \mu \mathrm{l}$ of DMSO was added into every well after removal of the medium to dissolve the crystals and incubation followed for $20 \mathrm{~min}$ at $37^{\circ} \mathrm{C}$. The absorbance was assessed at $492 \mathrm{~nm}$ using a microplate reader (model 550; Bio-Rad Laboratories, Inc., Hercules, CA, USA).

Cell apoptosis analysis. After transfection for 48 h, MCF-7 cells were seeded in a 6 -well-plate $\left(1-2 \times 10^{6}\right.$ cells) and were stained with $5 \mu \mathrm{l}$ Annexin V-APC and $5 \mu \mathrm{l}$ of propidium iodide (1 mg/ml) (KeyGen Biotech Co., Ltd., Nanjing, China) for $20 \mathrm{~min}$ in the dark. Cell apoptosis was assessed using a flow cytometer (FACSCalibur; BD Biosciences, Franklin Lakes, NJ, USA).

Cell migration assay. After transfection for $48 \mathrm{~h}, \mathrm{MCF}-7$ cells $\left(1 \times 10^{5}\right)$ were seeded in a 6 -well-plate $\left(1 \times 10^{5}\right.$ cells $)$ and the surface area of the cells was scratched with a 2-mm-wide tip. The plate was incubated with culture media in the presence for $24 \mathrm{~h}$. The cells in the upper Transwell chamber were removed 
A
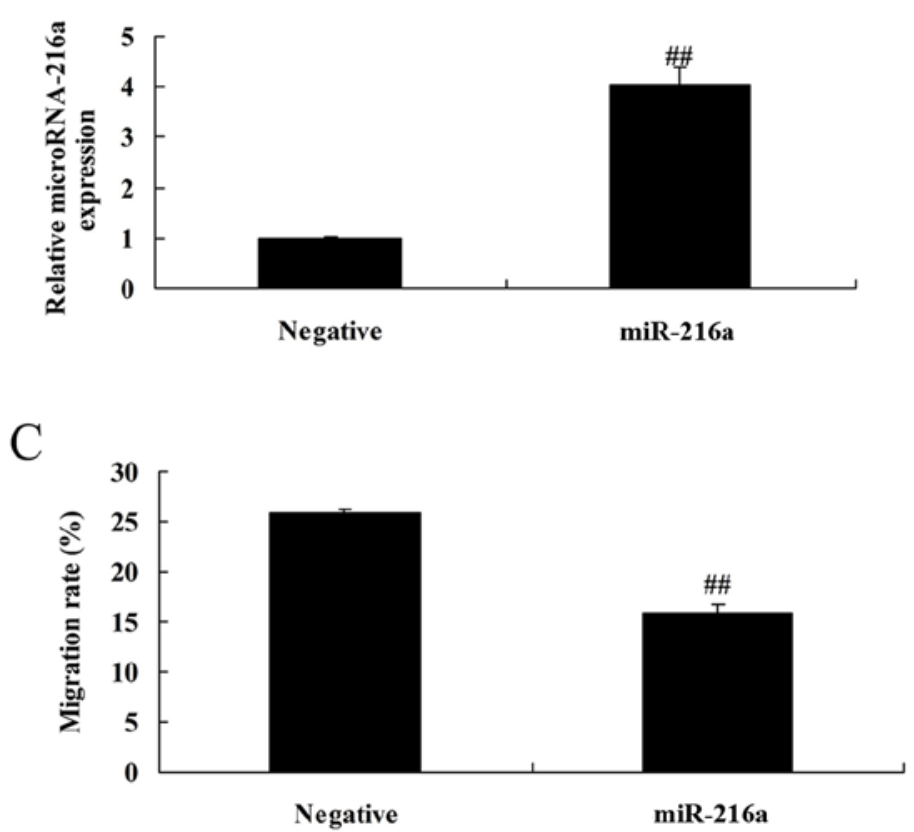

$\mathrm{B}$

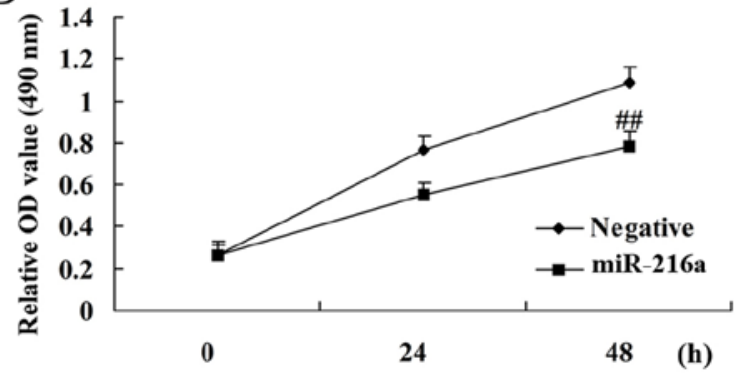

$\mathrm{D}$
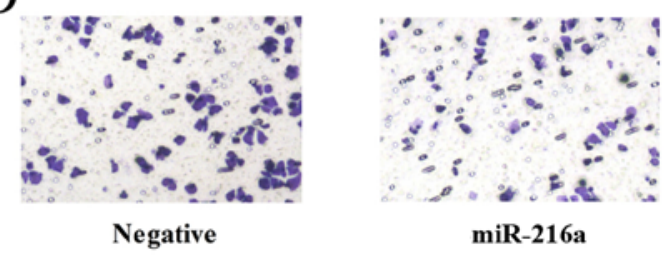

miR-216a

Figure 2. Overexpression of microRNA-216a reduces cell proliferation and migration of MCF-7 cells. (A) MicroRNA-216a expression, (B) cell proliferation, and $(\mathrm{C}$ and $\mathrm{D})$ the migration rate. Negative, negative control group; miR-216a, microRNA-216a overexpression group. ${ }^{\# \#} \mathrm{P}<0.01 \mathrm{compared}$ with the negative control group.

carefully with cotton swabs, and the cells that had migrated to the lower chamber were fixed in $75 \%$ ethanol, stained with $0.1 \%$ crystal violet and washed with PBS (HyClone; GE Healthcare Life Sciences, Logan, UT, USA). The rate of the cells migrating into the scratched area was assessed and images were captured using a fluorescence microscope (E1000M Eclipse; Nikon Corporation, Tokyo, Japan).

Caspase-3/9 kits. MCF-7 cells $\left(1 \times 10^{6}\right)$ were seeded in a 6-well-

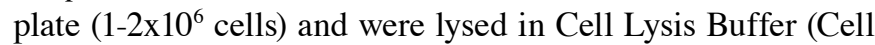
Signaling Technology, Inc., Danvers, MA, USA). Supernatants were harvested, and total protein was measured with a BCA assay (KeyGen Biotech Co., Ltd.). Total protein $(10 \mu \mathrm{g})$ was incubated with Ac-DEVD-pNA and Ac-IETD-pNA at $37^{\circ} \mathrm{C}$ for $1 \mathrm{~h}$. The absorbance was assessed at $405 \mathrm{~nm}$ using a microplate reader (model 550; Bio-Rad Laboratories, Inc.).

Western blotting. MCF-7 cells were seeded in a 6-well-plate (1-2x $10^{6}$ cells) and lysed in Cell Lysis Buffer (Cell Signaling Technology, Inc.). Supernatants were harvested, and total protein was assessed using a BCA assay (KeyGen Biotech Co., Ltd.). Total protein (40-80 $\mu \mathrm{g})$ was subjected to $10 \%$ SDS-PAGE and transferred onto nitrocellulose membranes (EMD Millipore, Billerica, MA, USA). The membranes were then blotted with primary antibodies against Bax (cat. no. sc-6236; 1:500), p53 (cat. no. sc-6243; 1:500), p21 (cat. no. sc-397; 1:500), $\beta$-catenin (cat. no. sc-7199; 1:500), cyclin D1 (cat. no. sc-717; 1:500) and GADPH (cat. no. sc-25778; 1:500; all from Santa Cruz Biotechnology, Inc., Dallas, TX, USA) at $4^{\circ} \mathrm{C}$ overnight. Incubation then followed with secondary antibody goat anti-rabbit IgG-HRP (cat. no. sc-2004; 1:5000; Santa Cruz Biotechnology, Inc.). The proteins were detected using ECL Plus Western Blotting Detection System (GE Healthcare
Life Sciences, Chalfont, UK). A protein blank was scanned with a Fujifilm LAS-3000 Imaging System and analyzed using MultiGauge Software (Fujifilm, Brookvale, Australia).

Statistical analysis. Comparisons among groups were determined by one-way ANOVA followed by Tukey's post-hoc test. The data are expressed as the mean \pm SD $(n=3) . P<0.05$ was considered to indicate a statistically significant difference.

\section{Results}

MicroRNA-216a expression in vivo. To assess the potential anticancer effects of microRNA-216a in human breast cancer, the expression of microRNA-216a was measured using quantitative real-time PCR. As presented in Fig. 1, serum microRNA-216a was significantly decreased in the breast cancer group compared with the control group.

MicroRNA-216a overexpression reduces the proliferation and migration of MCF-7 cells. The anticancer effects of microRNA216a on MCF-7 cells were assessed. MicroRNA-216a overexpression, induced by transfection with microRNA-216a mimics, significantly reduced the proliferation and migration of MCF-7 cells compared with control negative group (Fig. 2).

MicroRNA-216a overexpression induces apoptosis and increases caspase-3/8 activities in MCF-7 cells. MicroRNA-216a overexpression was demonstrated to significantly increase apoptosis and caspase-3/8 activities in MCF-7 cells compared with the negative control group (Fig. 3).

MicroRNA-216a overexpression promotes Bax and p53 protein expression in MCF-7 cells. The results revealed that 
A

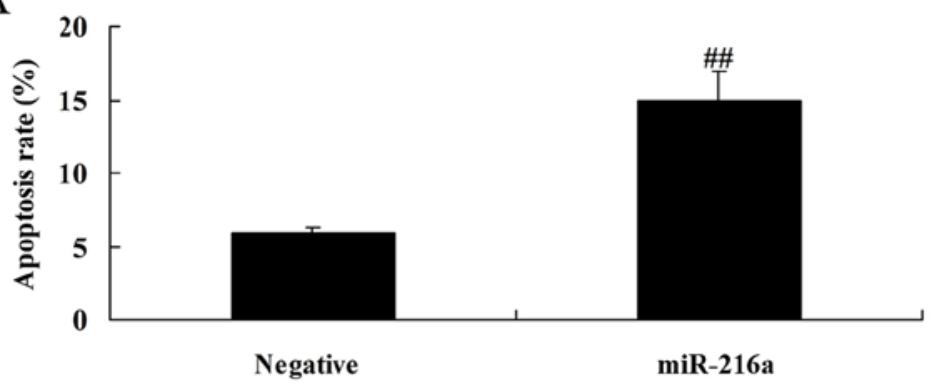

B

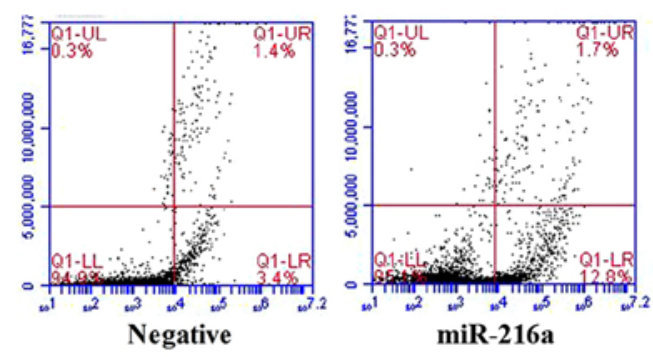

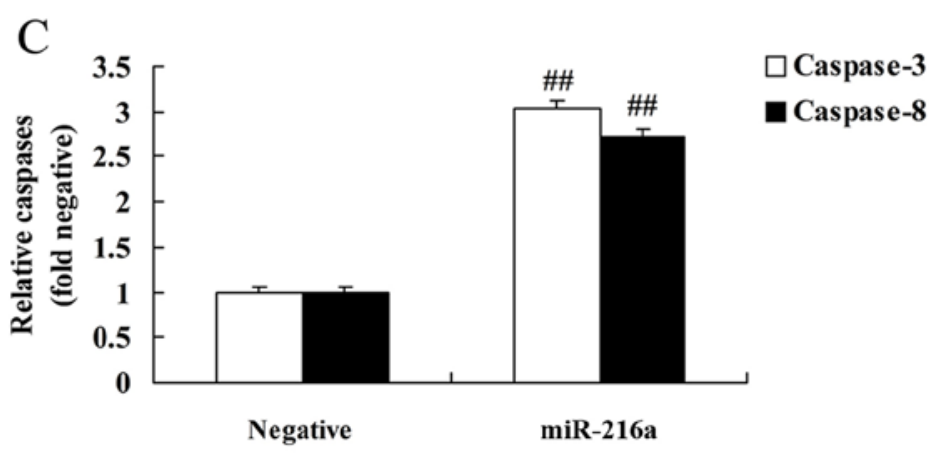

Figure 3. Overexpression of microRNA-216a induces apoptosis and increases caspase-3/8 activities of MCF-7 cells. (A and B) Apoptosis and (C) caspase-3/8 activities of MCF-7 cells. Negative, negative control group; miR-216a, microRNA-216a overexpression group. ${ }^{\# \prime} \mathrm{P}<0.01$ compared with the negative control group.

A

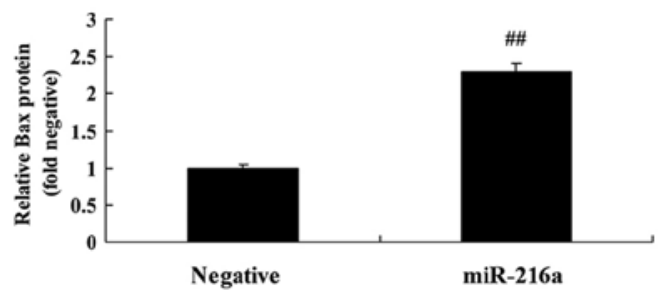

B

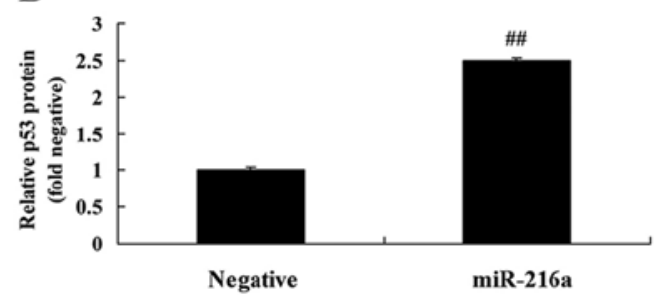

$\mathrm{C}$

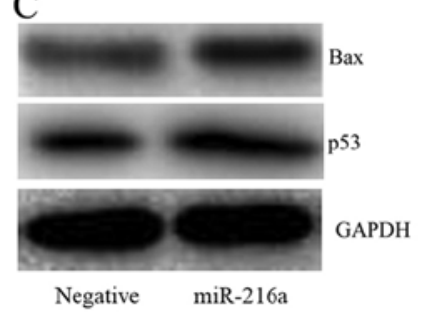

Figure 4. Overexpression of microRNA-216a promotes Bax and p53 protein expression of MCF-7 cells. (A and B) Bax and p53 protein expression assessed by statistical analysis and (C) western blot analysis for Bax and p53 protein expression of MCF-7 cells. Negative, negative control group; miR-216a, microRNA216a overexpression group. ${ }^{\# \prime} \mathrm{P}<0.01$ compared with the negative control group.

A

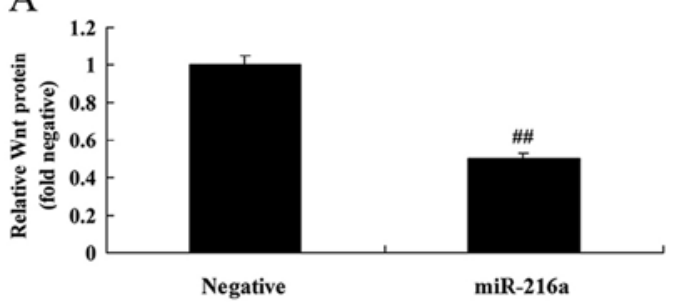

B

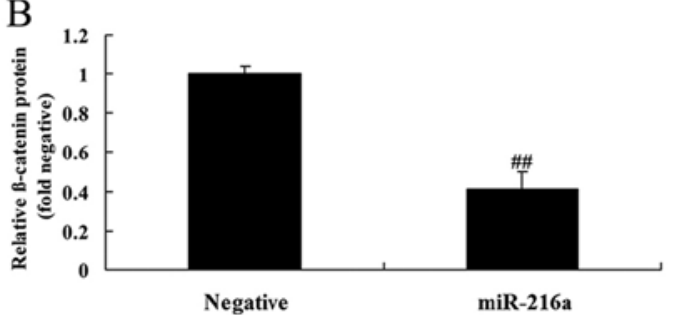

$\mathrm{C}$

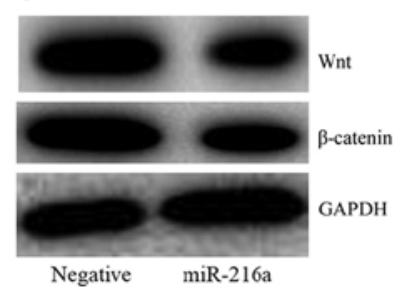

Figure 5. Overexpression of microRNA-216a suppresses Wnt and $\beta$-catenin protein expression of MCF-7 cells. (A and B) Wnt and $\beta$-catenin protein expression assessed by statistical analysis and (C) western blot analysis for Wnt and $\beta$-catenin protein expression of MCF-7 cells. Negative, negative control group; miR216a, microRNA-216a overexpression group. ${ }^{\# \#} \mathrm{P}<0.01$ compared with the negative control group.

overexpression of microRNA-216a significantly promoted Bax and 53 protein expression in MCF-7 cells compared with the negative control group (Fig. 4).

MicroRNA-216a overexpression suppresses Wnt and $\beta$-catenin protein expression in MCF-7 cells. To investigate the anticancer mechanisms of microRNA-216a in MCF-7 cells, Wnt and $\beta$-catenin protein expression was assessed. The results revealed that microRNA-216a overexpression significantly suppressed the expression of Wnt and $\beta$-catenin proteins in MCF-7 cells compared with the negative control group (Fig. 5). 
A
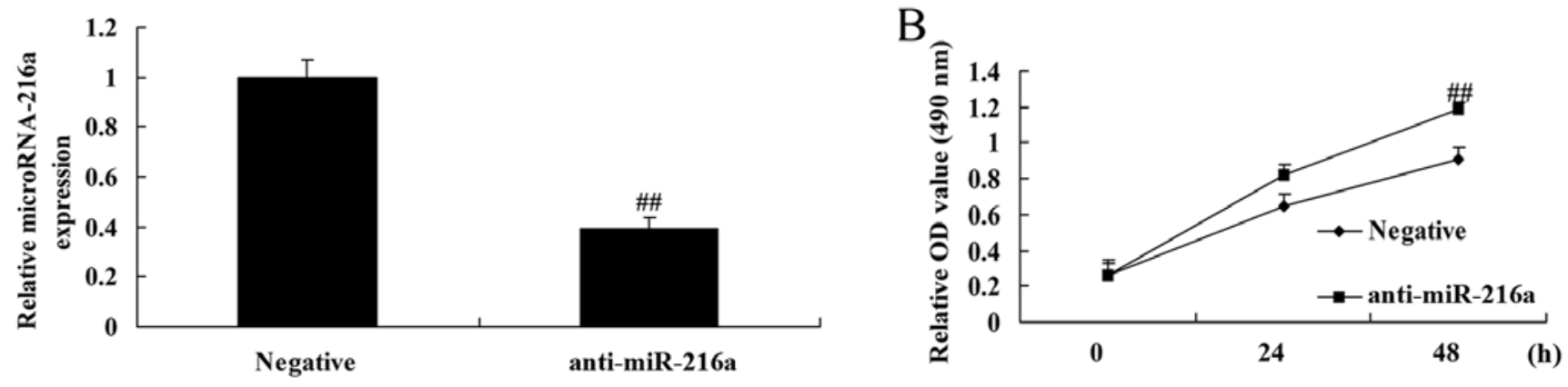

$\mathrm{C}$

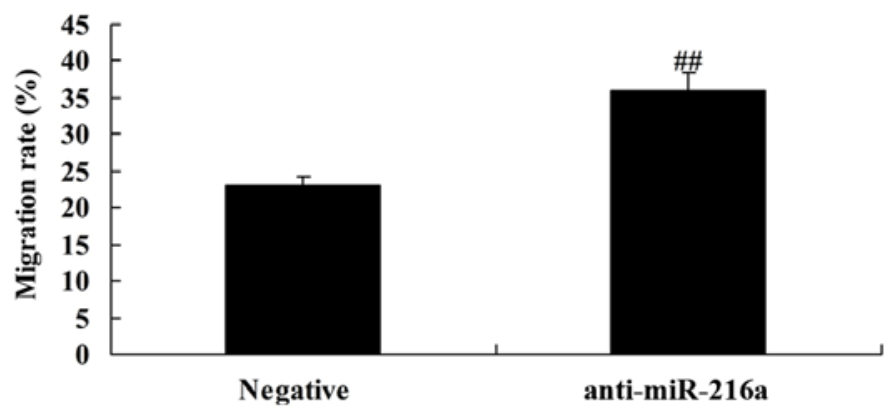

$\mathrm{D}$

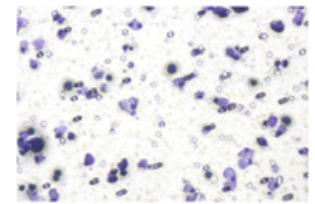

Negative

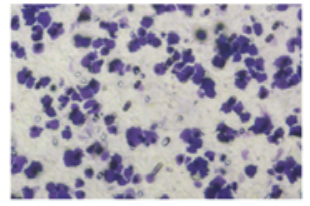

anti-miR-216a

Figure 6. Anti-microRNA-216a increases cell proliferation and migration of MCF-7 cells. (A) MicroRNA-216a expression, (B) cell proliferation and $(\mathrm{C}$ and $\mathrm{D})$ the migration rate. Negative, negative control group; anti-miR-216a, microRNA-216a-downregulated group. ${ }^{\# \#} \mathrm{P}<0.01$ compared with the negative control group.

A

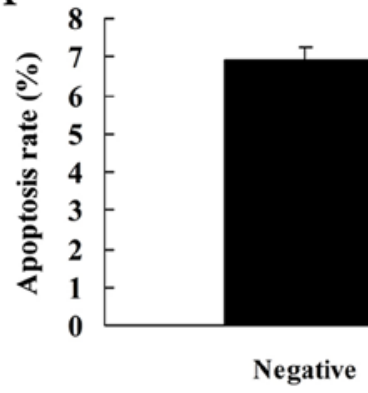

B
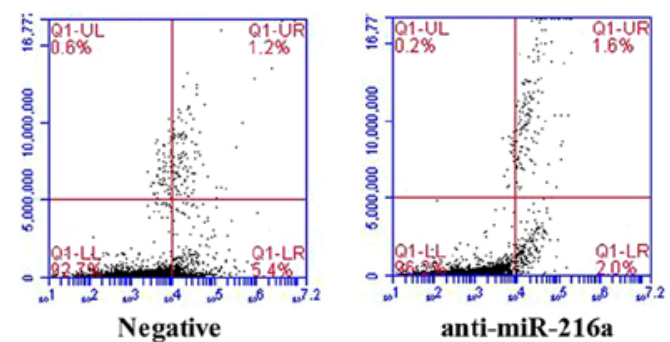

anti-miR-216a

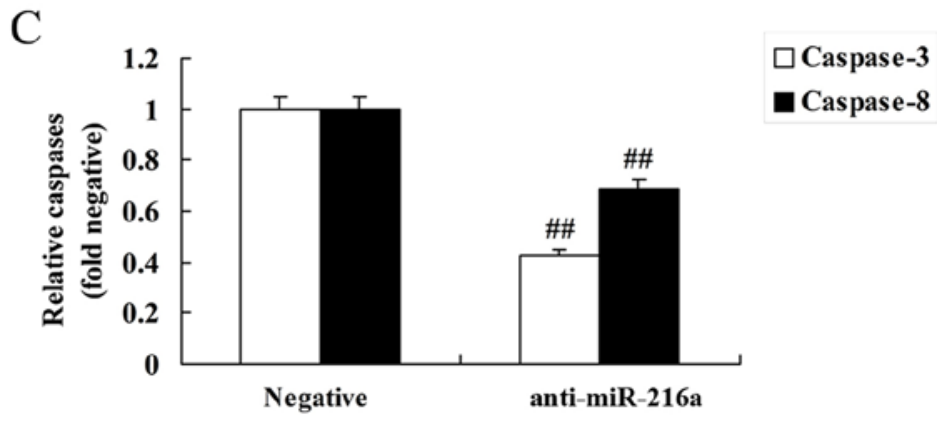

Figure 7. Anti-microRNA-216a decreases apoptosis and inhibits caspase-3/8 activities of MCF-7 cells. (A and B) Apoptosis and (C) caspase-3/8 activities of MCF-7 cells. Negative, negative control group; anti-miR-216a, microRNA-216a-downregulated group. ${ }^{\#} \mathrm{P}<0.01$ compared with the negative control group.

Anti-microRNA-216a increases the proliferation and migration of MCF-7 cells. Anti-microRNA-216a mimics were used to downregulate microRNA-216a in MCF-7 cells.
Following transfection with anti-microRNA-216a mimics, cell proliferation and migration were significantly increased in MCF-7 cells compared with the negative control group (Fig. 6). 

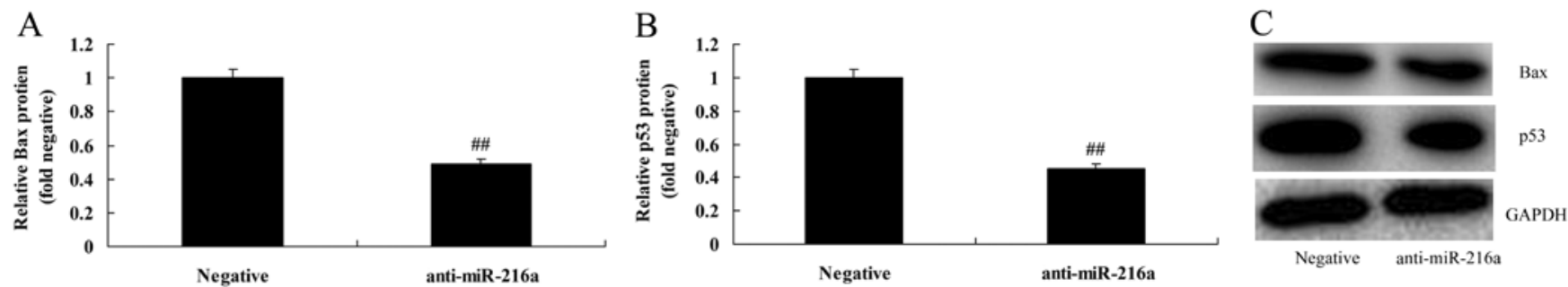

Figure 8. Anti-microRNA-216a suppresses Bax and p53 protein expression of MCF-7 cells. (A and B) Bax and p53 protein expression assessed by statistical analysis and (C) western blot analysis for Bax and p53 protein expression of MCF-7 cells. Negative, negative control group; anti-miR-216a, microRNA216a-downregulated group. ${ }^{\# \#} \mathrm{P}<0.01$ compared with the negative control group.
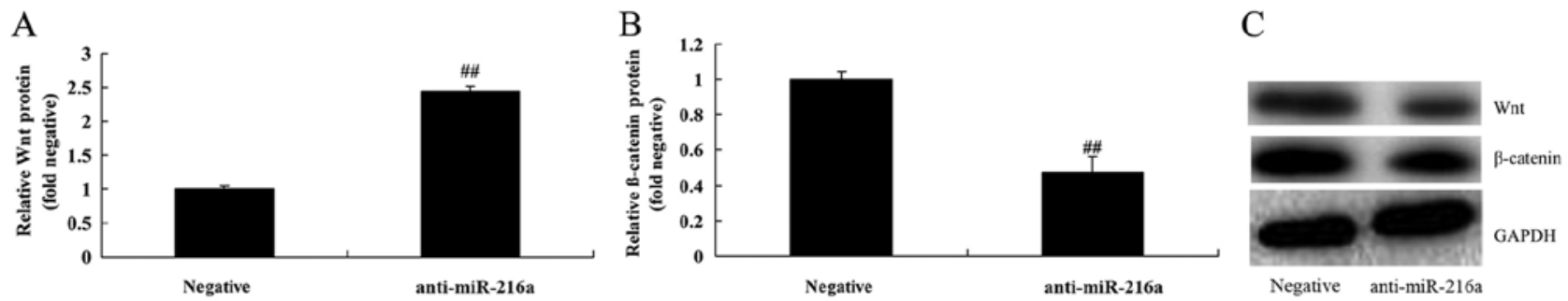

Figure 9. Anti-microRNA-216a promotes Wnt and $\beta$-catenin protein expression of MCF-7 cells. (A and B) Wnt and $\beta$-catenin protein expression assessed by statistical analysis and (C) western blot analysis for Wnt and $\beta$-catenin protein expression of MCF-7 cells. Negative, negative control group; anti-miR-216a, microRNA-216a-downregulated group. ${ }^{\# /} \mathrm{P}<0.01$ compared with the negative control group.

A

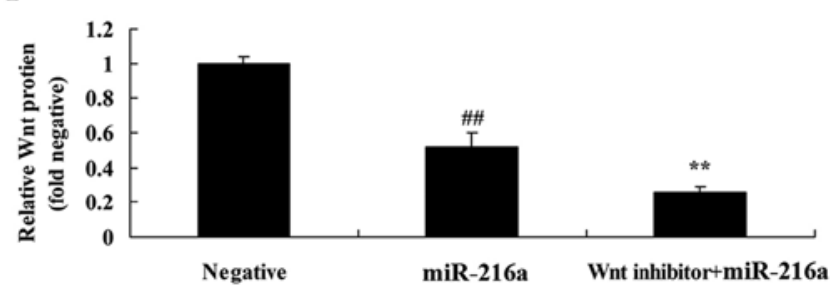

B

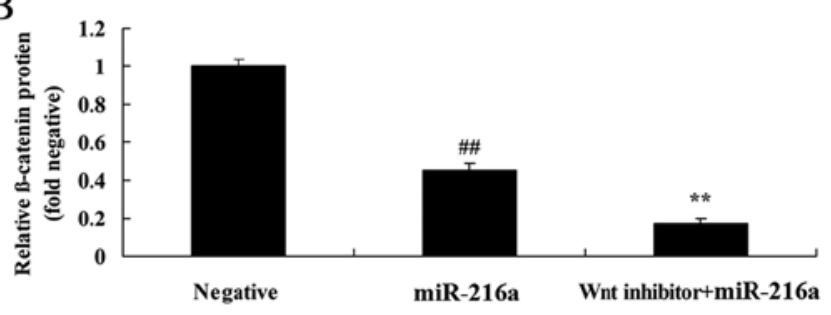

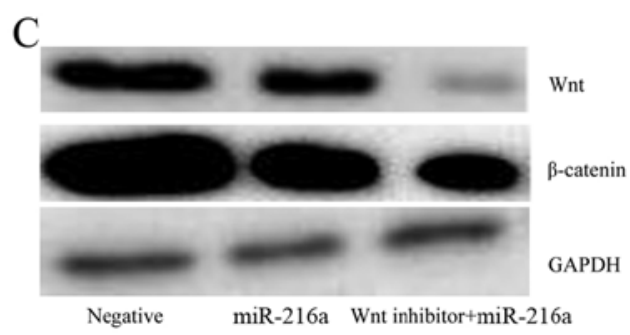

Figure 10. Inactivation of the Wnt pathway suppresses Wnt and $\beta$-catenin protein expression in MCF-7 cells following microRNA-216a treatment. Wnt and $\beta$-catenin protein expression by (A and B) statistical analysis and (C) western blot analysis for Wnt and $\beta$-catenin protein expression of MCF-7 cells. Negative, negative control group; miR-216a, microRNA-216a overexpression group; ${ }^{* \#} \mathrm{P}<0.01$ compared with the negative control group, ${ }^{* *} \mathrm{P}<0.01$ compared with microRNA-216a overexpression group.

Anti-microRNA-216a inhibits apoptosis and caspase-3/8 activities in MCF-7 cells. MicroRNA-216a inhibition resulted in a significant decrease in apoptosis and caspase-3/8 activities in MCF-7 cells compared with the negative control group (Fig. 7).

Anti-microRNA-216a suppresses Bax and 553 protein expression in MCF-7 cells. MicroRNA-216a inhibition significantly suppressed Bax and p53 protein expression in MCF-7 cells compared with the negative control group (Fig. 8).
Anti-microRNA-216a promotes Wnt and $\beta$-catenin protein expression in MCF-7 cells. To assess the anticancer mechanism of microRNA-216a in MCF-7 cells, Wnt and $\beta$-catenin expression was assessed. The results revealed that inhibition of microRNA-216a significantly promoted the expression of Wnt and $\beta$-catenin in MCF-7 cells compared with the negative control group (Fig. 9).

Wnt pathway inactivation suppresses Wnt and $\beta$-catenin expression in MCF-7 cells following treatment with 

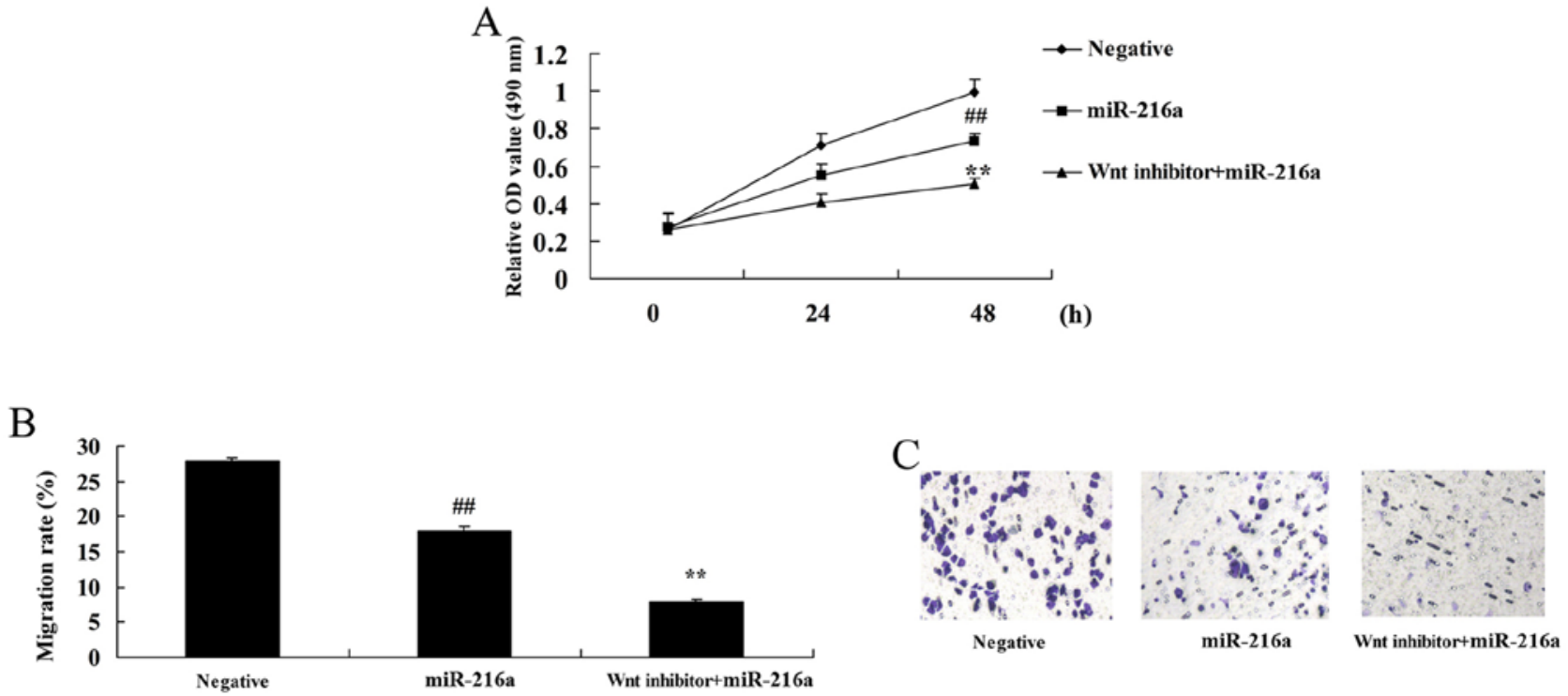

Figure 11. Inactivation of the Wnt pathway reduces cell proliferation and migration in MCF-7 cells following microRNA-216a treatment. (A) Cell proliferation and (B and C) the migration rate. Negative, negative control group; miR-216a, microRNA-216a overexpression group; ${ }^{\# \#} \mathrm{P}<0.01$ compared with the negative control group, ${ }^{* * *} \mathrm{P}<0.01$ compared with the microRNA-216a overexpression group.
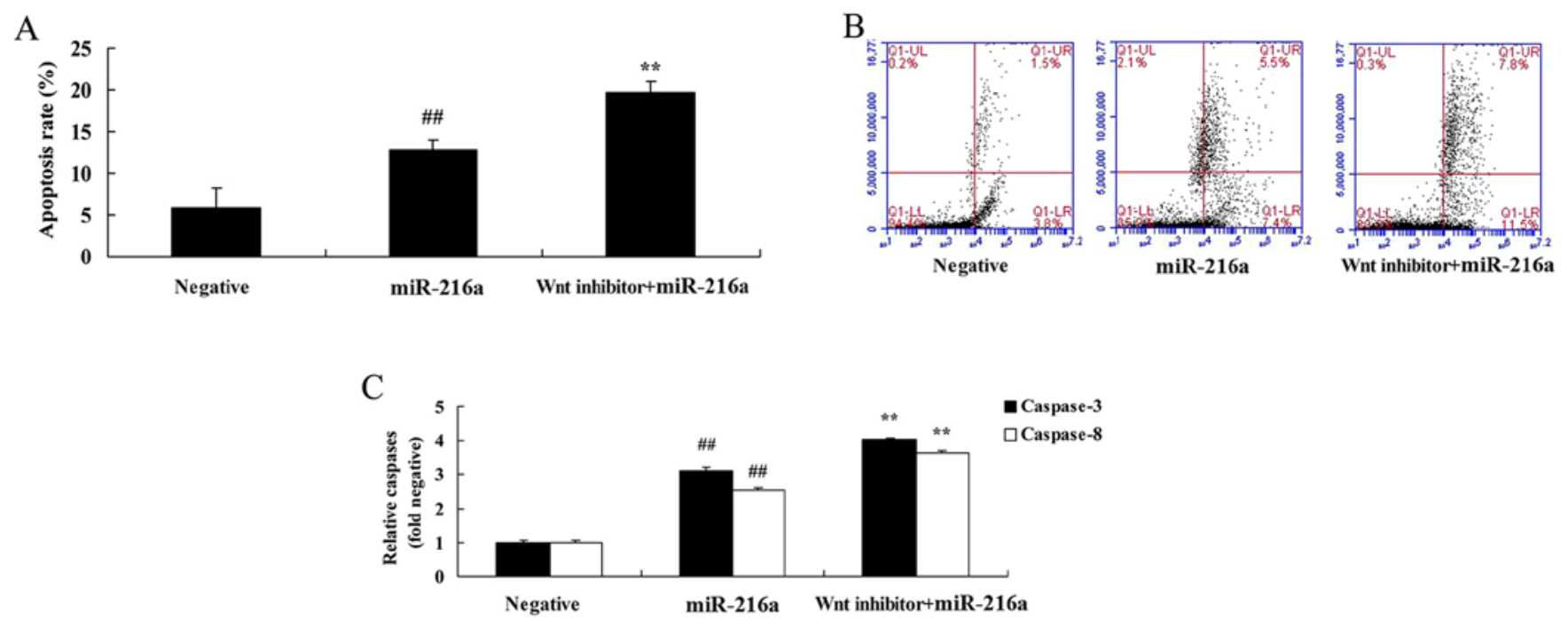

Figure 12. Inactivation of Wnt pathway induces apoptosis and increases caspase-3/8 activities in MCF-7 cells following microRNA-216a treatment. (A and B) Apoptosis and (C) caspase-3/8 activities of MCF-7 cells. Negative, negative control group; miR-216a, microRNA-216a overexpression group; ${ }^{\# \#} \mathrm{P}<0.01$ compared with the negative control group, ${ }^{* *} \mathrm{P}<0.01$ compared with the microRNA-216a overexpression group.

microRNA-216a. To confirm whether microRNA-216 acts by affecting Wnt in MCF-7 cells, the cells were treated with Wnt inhibitor (PNU-74654, $20 \mu \mathrm{M}$ ) for $48 \mathrm{~h}$. Wnt pathway inactivation led to a significant increase in the anticancer effects of microRNA-216; Wnt and $\beta$-catenin protein expression was inhibited compared with the with microRNA-216a alone group (Fig. 10).

Wht pathway inactivation reduces the proliferation and migration of MCF-7 cells following microRNA-216a treatment. Wnt pathway inactivation significantly reduced the proliferation and migration of MCF-7 cells following treatment with microRNA-216a compared with cells treated with microRNA-216a alone (Fig. 11).
Wht pathway inactivation induces apoptosis and increases caspase-3/8 activities in MCF-7 cells following microRNA-216a treatment. Compared with the microRNA-216a group, treatment with the Wnt inhibitor significantly induced apoptosis and increased caspase-3/8 activities in MCF-7 cells (Fig. 12).

Wnt pathway inactivation promotes Bax and p53 protein expression in MCF-7 cells following microRNA-216a treatment. To determine whether changes in Wnt inactivation occurred due to the effects of microRNA-216a on Bax and p53 protein expression, the expression levels of Bax and p53 in MCF-7 cells were assessed. Treatment with the Wnt inhibitor significantly promoted Bax and p53 protein expression in 
A

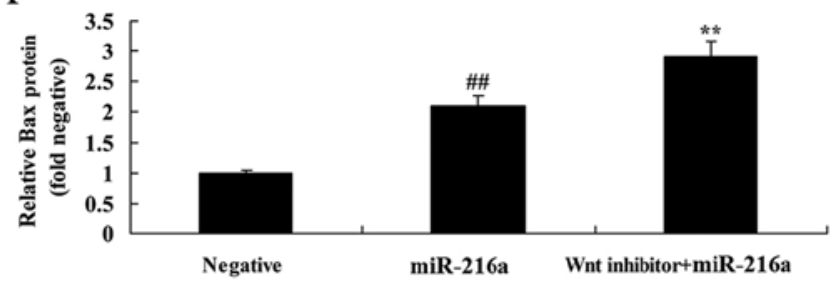

$\mathrm{B}$

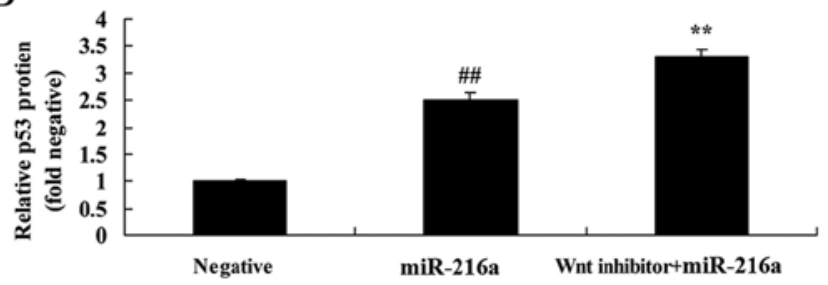

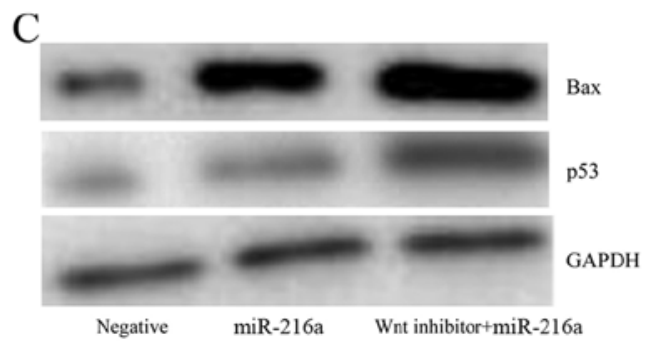

Figure 13. Inactivation of the Wnt pathway promotes Bax and p53 protein expression in MCF-7 cells following microRNA-216a treatment. (A and B) Bax and $\mathrm{p} 53$ protein expression by statistical analysis and (C) western blot analysis for Bax and p53 protein expression of MCF-7 cells. Negative, negative control group; miR-216a, microRNA-216a overexpression group; ${ }^{\# \#} \mathrm{P}<0.01$ compared with the negative control group, ${ }^{* *} \mathrm{P}<0.01$ compared with the microRNA-216a overexpression group.

MCF-7 cells following microRNA-216a treatment compared with cells treated with microRNA-216a alone (Fig. 13).

\section{Discussion}

According to statistics from the Union for International Cancer Control, breast cancer is a malignancy with high morbidity in women, accounting for $25 \%$. Each year, 1.2 million women develop breast cancer worldwide, of whom 500,000 succumb to the disease. The morbidity and mortality of breast cancer are the highest of all malignancies affecting females, and are increasing at an annual rate of $0.3-8 \%$ (17). In the USA, breast cancer accounts for $15.3 \%$ of all cancer morbidity, second only to prostate cancer, and has a mortality of $7.3 \%$. The morbidity and mortality of breast cancer varies between populations from different geographical regions, races and ethnic origins (18). The genesis of breast cancer is the accumulative result of multi-stage, multi-step and multi-gene abnormalities under the action of environmental and genetic factors, among which the key step is oncogene activation and inactivation of the tumor suppressor gene (19). The results of the present study demonstrated that serum microRNA-216a is significantly decreased in patients with breast cancer. MicroRNA-216a overexpression reduced the proliferation and migration, induced apoptosis, increased caspase-3/8 activities and promoted Bax and p53 expression in MCF-7 cells. Li et al reported that microRNA-216a inhibits growth and metastasis by targeting eukaryotic translation initiation factor 4B in oral squamous cell carcinoma (20). In the present study, we only used MCF-7 cells, which is a limitation. In future, more breast cancer cell lines or in vivo models of breast cancer should be studied. miRNA-126a may be a useful marker for monitoring responses to chemotherapy in the future.

The Wnt signal transduction pathway is a growth and development regulation pathway with multiple steps and multiple sites of action and is mediated by multiple intracellular and extracellular factors (21). Excessive activation and imbalance of the Wnt pathway induces dysplasia or tumor formation (22). The Wnt pathway is comprised of three pathways; the $\mathrm{Wnt} / \mathrm{Ca}^{2+}$ pathway, the PCP pathway and the canonical Wnt pathway (22). The canonical Wnt pathway is an important signal transduction pathway that triggers a cascade reaction via the specific binding of Wnt and the membrane receptor to alter intra-nuclear gene expression (6). The molecules involved in the canonical Wnt pathway include Wnt protein, Frizzled, E-cadherin, $\beta$-catenin, Dishevledr, APC protein, GSK-3 $\beta$ and Axin protein, as well as transcriptional factor/lymphoid enhancer factor and ubiquitin (23). In the present study, microRNA-216a suppressed Wnt and $\beta$-catenin protein expression in MCF-7 cells. Zhang et al suggested that microRNA-216a suppresses the proliferation, migration and invasion of glioma cells via the Wnt/ $\beta$-catenin signaling pathway (16). In the present study, only Wnt inhibitor + miR-216a were used. In future, Wnt inhibitor + anti-miR-216a should be utilized.

The Wnt signaling pathway regulates the embryogenesis and morphogenesis of tissues and organs in nematodes, fruit flies and even higher vertebrates (9). The Wnt pathway is inactive in normal mature cells, and the majority of $\beta$-catenin in the cytoplasm binds with E-cadherin. A small amount of $\beta$-catenin forms a protein polymer with GSK-3 $\beta$, APC and Axin; $\beta$-catenin in the polymer is phosphorylated, binds covalently with Ub and is degraded (24). Therefore, almost no free $\beta$-catenin is present in limitedly growing cells of the maturely and normally growing body in the absence of Wnt signaling. However, when the Wnt pathway is activated, Wnt binds with the cell surface receptor Fz and GSK-3 $\beta$ is inactivated, while $\beta$-catenin is not degraded under the participation of Dsh (6). When cytoplasmic $\beta$-catenin reaches a certain level it is transferred to the cell nucleus, accumulates gradually and enters the nucleus. Once there, it interacts with transcription factors, initiates transcription and regulates the expression of corresponding genes (25). The phosphorylation status of these 
components mediates the transmission of growth and development signals. Excessive transduction and abnormal activation may therefore give rise to malignant transformation of cells and tumor genesis (26). In the present study, it was determined that the anticancer effects of microRNA-216a were reversed by anti-microRNA-216a via the $\mathrm{Wnt} / \beta$-catenin signaling pathway. The microRNA-216a/Wnt/ $\beta$-catenin signaling pathway may regulate other cancers, and therefore, future studies should investigate the function of microRNA-216a in a range of tumor types. Meanwhile, microRNA-216a may also affect additional pathways to inhibit cell growth.

Wnt binding with $\mathrm{Fz}$ acts like a switch in the pathway; $\beta$-catenin is a critical component of the pathway that binds with E-cadherin and Tcf/Lef as well as forming complexes with GSK-3 $\beta$, APC and Axin. Cytoplasmic and nuclear $\beta$-catenin levels are altered via binding with a variety of components, thus affecting the expression of some genes $(27,28)$. In the present study, it was demonstrated that Wnt pathway inactivation increased the anticancer effects of microRNA-216a in MCF-7 cells, specifically proliferation and apoptosis. Zhang et al suggested that microRNA-216a suppresses the proliferation, migration, and invasion of glioma cells via the $\mathrm{Wnt} / \beta$-catenin signaling pathway (16). Collectively, these results revealed that microRNA-216a adjusts the Wnt/ $\beta$-catenin signaling pathway to induce apoptosis of breast cancer. The results of the present study indicated that microRNA-216a may be a novel treatment for targeting breast cancer cell growth via the Wnt/ $\beta$-catenin signaling pathway.

\section{Acknowledgements}

We would like to thank Dr Tianyun Wang and the International Joint Research Lab for Recombiant Pharmaceutical Protein Expression System of Henan for technical support.

\section{Funding}

This study was supported by the National Natural Science Foundation of China (no. 81502313) and the Doctoral Scientific Research Activation Foundation of Xinxiang Medical University (no. XYBSKYZZ201603).

\section{Availability of data and materials}

The analyzed data sets generated during the study are available from the corresponding author on reasonable request.

\section{Authors' contributions}

QX designed the experiment; SW, YZ, ZZ, CQ and XY performed the experiment; QX and SW analyzed the data; QX wrote the manuscript. All authors read and approved the final manuscript.

\section{Ethics approval and consent to participate}

All experimental protocols were approved by the Institutional Review Board of the Department of Laboratory Animal Science of School of Basic Medical Sciences, Xinxiang
Medical university (Xinxiang, China). Written informed consent was obtained from all participants.

\section{Patient consent for publication}

Not applicable.

\section{Competing interests}

The authors declare that they have no competing interests.

\section{References}

1. Taylor-Phillips S, Wallis MG, Jenkinson D, Adekanmbi V, Parsons H, Dunn J, Stallard N, Szczepura A, Gates S, Kearins O, et al: Effect of using the same vs different order for second readings of screening mammograms on rates of breast cancer detection: A randomized clinical trial. JAMA 315: 1956-1965, 2016.

2. Pu Z, Zhang X, Chen Q, Yuan X and Xie H: Establishment of an expression platform of OATP1B1 388GG and 521CC genetic polymorphism and the therapeutic effect of tamoxifen in MCF-7 cells. Oncol Rep 33: 2420-2428, 2015.

3. Moss SM, Wale C, Smith R, Evans A, Cuckle H and Duffy SW: Effect of mammographic screening from age 40 years on breast cancer mortality in the UK Age trial at 17 years' follow-up: A randomised controlled trial. Lancet Oncol 16: 1123-1132, 2015.

4. Pei L, Zhou Y, Tan G, Mao F, Yang D, Guan J, Lin Y, Wang X, Zhang Y, Zhang X, et al; Outcomes research consortium: ultrasound-assisted thoracic paravertebral block reduces intraoperative opioid requirement and improves analgesia after breast cancer surgery: A randomized, controlled, single-center trial. PLoS One 10: e0142249, 2015

5. Sun X, Xu C, Tang SC, Wang J, Wang H, Wang P, Du N, Qin S, Li G, Xu S, et al: Let-7c blocks estrogen-activated Wnt signaling in induction of self-renewal of breast cancer stem cells. Cancer Gene Ther 23: 83-89, 2016

6. Lii CK, Chang JW, Chen JJ, Chen HW, Liu KL, Yeh SL, Wang TS, Liu SH, Tsai CH and Li CC: Docosahexaenoic acid inhibits 12-O-tetradecanoylphorbol-13-acetate-induced fascin1-dependent breast cancer cell migration by suppressing the PKC $\delta$ - and Wnt-1/ $\beta$-catenin-mediated pathways. Oncotarget 7 : 25162-25179, 2016

7. Morrow KA, Das S, Meng E, Menezes ME, Bailey SK, Metge BJ, Buchsbaum DJ, Samant RS and Shevde LA: Loss of tumor suppressor Merlin results in aberrant activation of Wnt $/ \beta$-catenin signaling in cancer. Oncotarget 7: 17991-18005, 2016.

8. Wei H, Wang H, Ji Q, Sun J, Tao L and Zhou X: NRBP1 is downregulated in breast cancer and NRBP1 overexpression inhibits cancer cell proliferation through $\mathrm{Wnt} / \beta$-catenin signaling pathway. Onco Targets Ther 8: 3721-3730, 2015.

9. Cui J, Li P, Liu X, Hu H and Wei W: Abnormal expression of the Notch and Wnt/ $\beta$-catenin signaling pathways in stem-like ALDHhiCD $44^{+}$cells correlates highly with $\mathrm{Ki}-67$ expression in breast cancer. Oncol Lett 9: 1600-1606, 2015.

10. Farahmand L, Darvishi B, Majidzadeh AK and Madjid Ansari A: Naturally occurring compounds acting as potent anti-metastatic agents and their suppressing effects on Hedgehog and WNT/ beta-catenin signalling pathways. Cell Prolif 50: e12299, 2017.

11. Li K, Ying M, Feng D, Du J, Chen S, Dan B, Wang C and Wang Y: Fructose-1,6-bisphosphatase is a novel regulator of $\mathrm{Wnt} / \beta$ Catenin pathway in breast cancer. Biomed Pharmacother 84: 1144-1149, 2016.

12. Shrivastava S, Jeengar MK, Thummuri D, Koval A, Katanaev VL, Marepally S and Naidu VGM: Cardamonin, a chalcone, inhibits human triple negative breast cancer cell invasiveness by downregulation of $\mathrm{Wnt} / \mathrm{\beta}$-catenin signaling cascades and reversal of epithelial-mesenchymal transition. Biofactors 43: 152-169, 2017.

13. Li Y, Cai B, Shen L, Dong Y, Lu Q, Sun S, Liu S, Ma S, Ma PX and Chen J: MiRNA-29b suppresses tumor growth through simultaneously inhibiting angiogenesis and tumorigenesis by targeting Akt3. Cancer Lett 397: 111-119, 2017.

14. Das S: Identification and targeting of microRNAs modulating acquired chemotherapy resistance in Triple negative breast cancer (TNBC): A better strategy to combat chemoresistance. Med Hypotheses 96: 5-8, 2016. 
15. Liu B, Su F, Chen M, Li Y, Qi X, Xiao J, Li X, Liu X, Liang W, Zhang Y, et al: Serum miR-21 and miR-125b as markers predicting neoadjuvant chemotherapy response and prognosis in stage II/III breast cancer. Hum Pathol 64: 44-52, 2017.

16. Zhang J, Xu K, Shi L, Zhang L, Zhao Z, Xu H, Liang F, Li H, Zhao Y, Xu X, et al: Overexpression of microRNA-216a suppresses proliferation, migration, and invasion of glioma cells by targeting leucine-rich repeat-containing $\mathrm{G}$ protein-coupled receptor 5. Oncol Res 25: 1317-1327, 2017.

17. Liu M, Wang S, Cui S, Duan X, Fan Z and Yu Z: The feasibility of the ACOSOG Z0011 Criteria to Chinese Breast Cancer Patients: A multicenter study. Sci Rep 5: 15241, 2015.

18. Li T, Wang B, Wang Z, Ragaz J, Zhang J, Sun S, Cao J, Lv F, Wang L, Zhang S, et al: Bevacizumab in combination with modified FOLFOX6 in heavily pretreated patients with HER2/ neu-negative metastatic breast cancer: A Phase II Clinical Trial. PLoS One 10: e0133133, 2015.

19. Láng I, Bell R, Feng FY, Lopez RI, Jassem J, Semiglazov V, Al-Sakaff N, Heinzmann D and Chang J: Trastuzumab retreatment after relapse on adjuvant trastuzumab therapy for human epidermal growth factor receptor 2-positive breast cancer: Final results of the Retreatment after HErceptin Adjuvant trial. Clin Oncol (R Coll Radiol) 26: 81-89, 2014

20. Li L and Ma HQ: MicroRNA-216a inhibits the growth and metastasis of oral squamous cell carcinoma by targeting eukaryotic translation initiation factor 4B. Mol Med Rep 12: 3156-3162, 2015

21. Vadnais C, Shooshtarizadeh P, Rajadurai CV, Lesurf R, Hulea L, Davoudi S, Cadieux C, Hallett M, Park M and Nepveu A: Autocrine activation of the Wnt/ $\beta$-catenin pathway by CUX1 and GLIS1 in breast cancers. Biol Open 3: 937-946, 2014.
22. Yin L, Gao Y, Zhang X, Wang J, Ding D, Zhang Y, Zhang J and Chen H: Niclosamide sensitizes triple-negative breast cancer cells to ionizing radiation in association with the inhibition of Wnt/3-catenin signaling. Oncotarget 7: 42126-42138, 2016.

23. Ahmed K, Shaw HV, Koval A and Katanaev VL: A second WNT for old drugs: Drug repositioning against WNT-dependent cancers. Cancers (Basel) 8: pii: E66, 2016.

24. Guo L, Yilamu D, Sun L, Liu S and Ma F: Association among the expression of $\beta$-catenin, cyclin D1 and estrogen receptor- $\beta$ in human breast cancer. Exp Ther Med 10: 1423-1428, 2015.

25. Lu W, Lin C and Li Y: Rottlerin induces Wnt co-receptor LRP6 degradation and suppresses both Wnt $/ \beta$-catenin and mTORC1 signaling in prostate and breast cancer cells. Cell Signal 26: 1303-1309, 2014

26. Lill C, Schneider S, Ghanim B, Brunner M, Heiduschka G, Loewe R and Thurnher D: Expression of $\beta$-catenin and cyclin D1 in Merkel cell carcinomas of the head and neck. Wien Klin Wochenschr 125: 501-507, 2013.

27. Zhou XL, Qin XR, Zhang XD and Ye LH: Downregulation of Dickkopf-1 is responsible for high proliferation of breast cancer cells via losing control of Wnt/beta-catenin signaling. Acta Pharmacol Sin 31: 202-210, 2010.

28. Zhang J, Yang Z, Li P, Bledsoe G, Chao L and Chao J: Kallistatin antagonizes Wnt/ $\beta$-catenin signaling and cancer cell motility via binding to low-density lipoprotein receptor-related protein 6 . Mol Cell Biochem 379: 295-301, 2013.

This work is licensed under a Creative Commons Attribution-NonCommercial-NoDerivatives 4.0 International (CC BY-NC-ND 4.0) License. 